\title{
Melanin Production by Aspergillus nidulans in Batch and Chemostat Cultures
}

\author{
By B. I. ROWLEY* AND S. J. PIRT \\ Department of Microbiology, Queen Elizabeth College, \\ University of London, London, W. 8
}

(Received 18 October $197 \mathrm{I}$; revised 9 May 1972)

\begin{abstract}
SUMMAR Y
In batch culture melanin production by Aspergillus nidulans occurred after the cessation of exponential growth. Melanin production in the chemostat was favoured when the growth rate was a relatively small fraction of the maximum growth rate under the prevailing culture conditions. Growth-limitation by the carbon source induced melanogenesis more strongly than did growth-limitation by the nitrogen source. Melanin production was maximal within the dissolved oxygen tension range 16 to $30 \mathrm{mmHg}$; it increased with temperature in the range 20 to $37^{\circ} \mathrm{C}$ and with increase in $\mathrm{pH}$ up to $7 \cdot 9$. At high temperature and high $\mathrm{pH}$ the ability to produce melanin declined. The melanin was variable in composition. Both soluble and insoluble forms were produced. The soluble form appeared to be less highly polymerized than the insoluble form which was laid down on the hyphal walls and had a microfibrillar structure revealed by the electron microscope.
\end{abstract}

\section{INTRODUCTION}

The widespread and variable group of brown and black pigments known as melanins have been defined in various ways. Thomas (1955) restricted the term to indole derivatives whilst Mason (1959) included pigments formed by the enzymatic oxidation of non-nitrogenous phenols. Andrews \& Pridham (1967) have found that plant pigments of the melanin type vary considerably with respect to their nitrogen content. Bull (1970 $b$ ) characterized the melanin of Aspergillus nidulans, found its nitrogen content may vary from 3.25 to $5.82 \%$, and identified indolic residues amongst its degradation products. It has been reported that Ustilago maydis melanin consists of a catechol-derived polymer (Nicolaus, Piattelli \& Fattorusso, 1964) but it is not yet known if catechol is normally incorporated into the $A$. nidulans melanin.

A number of workers (see Bull, $1970 b$ ) have recently presented a case for a biological role of fungal melanin in protecting the hyphae against microbial lysis in soils. Bull (1970a) has shown that melanized hyphal walls of Aspergillus nidulans varied in their susceptibility to lysis by $\beta$-I,3-glucanase and chitinase according to the extent of pigmentation. He concluded that the effect was probably a combination of enzyme inhibition and substrate complexing by melanin. Other suggested functions of fungal melanins include alteration in the transport of solutes in apple leaves by melanoprotein produced by Venturia inaequalis (Hignett \& Kirkham, 1967) and protection against u.v. light by the melanin coating on walls of Aureobasidium pullulans (Durrell, 1968).

Little information has previously been published on the factors controlling fungal melanin

* Present address: Biological Laboratory, The University, Canterbury, Kent. 
production. It appears to be a secondary metabolite for it is produced after exhaustion of the carbon source in batch culture (Pirt \& Rowley, 1969). Horowitz \& Shen (1952) found that the use of sulphate-deficient growth media favoured the production of melanin by Neurospora crassa. In the present paper, a detailed study of melanin production by Aspergillus nidulans under various growth conditions is described.

The aim of the present work is to contribute to knowledge of the factors influencing fungal melanin formation and of the nature of melanin itself. A preliminary report of this investigation has been published elsewhere (Pirt \& Rowley, 1969). The project was part of an interdisciplinary research programme and for details of other aspects of the work reference should be made to Carter \& Bull (I969, I97I), Bainbridge et al. (197I), Carter, Bull, Pirt \& Rowley (197I) and Martinelli \& Bainbridge (I972).

\section{METHODS}

Culture apparatus. Porton-type fermenters adapted for cultivation of filamentous microorganisms (Righelato \& Pirt, 1967) were used. Other modifications to reduce fungal growth on surfaces included the sheathing of internal parts with polytetrafluoroethylene (Polypenco Ltd., Welwyn Garden City, Hertfordshire) and the use of an eight-bladed, paddle-type stirrer operating close (clearance, 3 to $4 \mathrm{~mm}$ ) to the fermenter base.

Culture techniques. Batch- and chemostat-cultures (2 to 31$)$ were aerated by vortex stirring (impeller speed, 1400 to $1440 \mathrm{rev} . / \mathrm{min}$ ). Temperature was controlled at $30^{\circ} \mathrm{C}$ unless otherwise stated. In chemostat cultures the $\mathrm{pH}$-value was controlled, by automatic addition of $2 \mathrm{~N}^{-} \mathrm{H}_{2} \mathrm{SO}_{4}$, at 6.7 (i.e. at the $\mathrm{pH}$ of the growth medium) or at other values as stated. Control of dissolved oxygen tension in the chemostat was as described by MacLennan \& Pirt (1967). Unless specifically mentioned, the dissolved oxygen tension was not automatically controlled but was kept in the range 130 to $150 \mathrm{mmHg}$. Polypropylene glycol $\mathrm{P} 2000$ (about $0.5 \mathrm{ml} / 1$ medium) was added to control foaming.

In a series of chemostat experiments, steady states were obtained at different values of dilution rate, temperature, dissolved oxygen tension and $\mathrm{pH}$ value. Unless stated otherwise, these parameters were maintained at the values stated above.

Melanin production by Aspergillus nidulans in shake-flasks was enhanced by the presence of iron in culture media and drastically reduced by metal-chelating agents (ethylene diamine tetra-acetic acid, citric acid) unless these were used at a concentration barely sufficient to prevent precipitation during autoclaving. Since there are several reports implicating metals in the enhancement of melanin production, a medium rich in trace metals was developed. The importance of copper, iron and cobalt in this respect was suggested by Kikkawa, Ogita \& Fujito (1955) and that of manganese by Brandt (1962). This growth medium, a glucose-nitrate-mineral salts mixture was as described by Bainbridge et al. (197I) but with $12.5 \mathrm{~g} / \mathrm{l}$ glucose unless otherwise stated. Changes in culture conditions were made gradually to avoid physiological shocks to the organism.

Organism. Strain BWB224 (GLASGOW) of Aspergillus nidulans (Eidam) Wint. was used. This is a yellow-sporing, prototrophic recombinant (ve y) with a velvet morphology. The organism was maintained on slopes of Oxoid malt extract agar. Subcultures were incubated at $30^{\circ} \mathrm{C}$ for 3 days. Fermenters were inoculated with conidial suspensions to give a final concentration of $10^{6}$ to $10^{7}$ conidia $/ \mathrm{ml}$. of medium.

Analytical methods. The organism concentration was measured as biomass $(\mathrm{g} / \mathrm{l})$ after flltration of $10 \mathrm{ml}$ culture (sintered crucible, porosity 2), twice washing with water, and drying at $105{ }^{\circ} \mathrm{C}$ for $24 \mathrm{~h}$; the culture dry weight so obtained was corrected for its insoluble 
melanin content to give the biomass. This was considered advisable because the insoluble melanin was an inert coating highly variable in thickness on the outside of the hyphal wall.

The soluble melanin concentration in culture filtrates was determined in terms of a standard soluble melanin by measuring the extinction at $425 \mathrm{~nm}$ of the filtrate adjusted if necessary to $\mathrm{pH} 6 \cdot 7 \pm 0 \cdot \mathrm{I}$. The standard soluble melanin used was obtained from the filtrate of a chemostat culture of Aspergillus nidulans (dilution rate, $0.025 \mathrm{~h}^{-1}$ ) as described under melanin investigations. The assay developed for insoluble melanin was based upon the extraction of fungal mycelium by shaking anaerobically with $\mathrm{N}-\mathrm{NaOH}$ at room temperature for $4 \mathrm{~h}$. The exclusion of air from alkaline melanin solutions was essential to prevent their fading. Fuller details of the method are given by Bainbridge et al. (I97I). The standard deviation of this assay was calculated as $\pm 8 \%$ from a wide range of triplicate results. Insoluble melanin concentrations were expressed in terms of an $A$. nidulans insoluble melanin standard extracted from pigmented mycelium.

Glucose concentrations in culture filtrates were measured by a glucose-oxidase method. Total carbohydrate in fungal mycelium was determined by mixing culture samples $(2 \mathrm{ml})$ with $2 \mathrm{~N}-\mathrm{NaOH}(8 \mathrm{ml})$ and allowing the mixtures to stand for $24 \mathrm{~h}$ to allow oxidative fading of melanin. Assays were performed on the mixtures by the method of Trevelyan \& Harrison (1952) except that the anthrone reagent was aged for $24 \mathrm{~h}$ before use. Carbohydrate concentrations were expressed in terms of a glucose standard. If excess glucose was present in culture samples, this was first removed by washing. Nitrate was measured by a colorimetric method using brucine (Walther, I966). Test solutions were read at $425 \mathrm{~nm}$. Nitrite was determined by the Griess-Ilosvay procedure and carbon, hydrogen and nitrogen determinations were made with a Perkin-Elmer 240 elemental analyser.

Carbon dioxide and oxygen concentrations in the effluent gas from fermenters were measured as described by Rowley (1970). The results of gas analyses and soluble melanin determinations were used in deciding when a steady state had been attained in chemostat cultures.

Melanin investigations. Insoluble melanin was extracted from pigmented mycelium as described by Bainbridge et al. (1971). Soluble melanin was precipitated from culture filtrates by adjusting the $\mathrm{pH}$ to $2 \cdot 2 \pm 0 \cdot 2$ with $\mathrm{HCl}$. After washing with water the precipitated material was dried over $\mathrm{P}_{2} \mathrm{O}_{5}$ in vacuo. Spectra of melanin solutions in $\mathrm{N}-\mathrm{NaOH}$ were prepared by using an SP 800 B spectrophotometer (Unicam Instruments Ltd, York St, Cambridge).

Electron microscopy. Mycelium was fixed by glutaraldehyde $(3.85 \%$, w/v) in cacodylate buffer (0.05 $\mathrm{M} ; \mathrm{pH} 7 \cdot 2$ to $7 \cdot 4$ ) for $\mathrm{I}$ h, then (unless otherwise stated) in osmic acid (I \%, w/v) in veronal acetate buffer $(0.05 \mathrm{M})$ for $2 \mathrm{~h}$. Dehydration was by a graded series of ethanol solutions; then after $20 \mathrm{~min}$ in propylene oxide the material was transferred to Araldite. Sectioning was by an LKB Ultratome III using glass knives. Sections were picked up on uncoated copper grids, stained by $2 \%(\mathrm{w} / \mathrm{v})$ uranyl acetate $(20 \mathrm{~min})$ followed by $3 \mathrm{~min}$ in lead citrate (Reynolds, 1963), and examined in an AEI EM 6B electron microscope.

\section{RESULTS}

\section{Melanin production in glucose-limited batch and chemostat cultures}

During unlimited growth in batch culture, melanin was not produced by Aspergillus nidulans. When growth ceased, owing to exhaustion of the carbon source (glucose), soluble and insoluble melanins were produced over a period of many hours. During this time a reduction in the mycelial carbohydrate concentration was observed. No satisfactory assay for protein in the presence of melanin could be found. 
Table I. Relationships between dilution rate and melanin production, specific oxygen utilization rate $\left(q-\mathrm{O}_{2}\right)$ and respiratory quotient (R.Q.) of Aspergillus nidulans in chemostat culture

The dissolved oxygen tension was $140 \mathrm{mmHg}$.

\begin{tabular}{|c|c|c|}
\hline $\begin{array}{l}\text { Dilution } \\
\text { rate }\left(\mathrm{h}^{-1}\right)\end{array}$ & $\begin{array}{l}\text { q-Soluble melanin } \\
(\mathrm{mg} / \mathrm{g} \text { biomass } / \mathrm{h})\end{array}$ & $\begin{array}{l}\text { q-Insoluble melanin } \\
(\mathrm{mg} / \mathrm{g} \text { biomass } / \mathrm{h})\end{array}$ \\
\hline 0.025 & $6 \cdot 53$ & $6 \cdot 8 I$ \\
\hline 0.05 & $\mathrm{I} \cdot 02$ & $3.5 \mathrm{I}$ \\
\hline \multirow[t]{2}{*}{0.07} & $\mathrm{I} \cdot 48$ & 3.05 \\
\hline & $\begin{array}{c}\text { Soluble melanin } \\
\text { yield } \\
(\mathrm{mg} / \mathrm{g} \text { glucose })\end{array}$ & $\begin{array}{c}\text { Insoluble melanin } \\
\text { yield } \\
\text { (mg/g glucose) }\end{array}$ \\
\hline 0.025 & $92 \cdot 0$ & $95 \cdot I$ \\
\hline 0.05 & 9.03 & $3 I \cdot I$ \\
\hline \multirow[t]{2}{*}{0.07} & $7 \cdot 33$ & $15 \cdot I$ \\
\hline & $\begin{array}{c}\mathrm{q}-\mathrm{O}_{2}(\mathrm{mmol} / \mathrm{g} \\
\text { biomass } / \mathrm{h})\end{array}$ & R.Q. \\
\hline 0.025 & $\mathrm{I} \cdot 04$ & I $\cdot 08$ \\
\hline 0.05 & $I \cdot I 5$ & $I \cdot 27$ \\
\hline 0.07 & $I \cdot 9 I$ & I. 47 \\
\hline
\end{tabular}

Melanin production was induced in chemostat cultures by glucose-limited growth. The effects of growth rate (equal to dilution rate in a chemostat steady state) upon melanin production and gas exchange are shown in Table $\mathrm{I}$. As would be expected on the grounds of increased metabolic activity, the specific oxygen utilization rate $\left(\mathrm{q}-\mathrm{O}_{2}, \mathrm{mmol} \mathrm{O}_{2} / \mathrm{g}\right.$ biomass $\left./ \mathrm{h}\right)$ increased with growth rate. The increase in respiratory quotient (R.Q., q-CO $\mathrm{CO}_{2} / \mathrm{q}-\mathrm{O}_{2}$ ) with growth rate could not be explained but may indicate a change in the manner of glucose catabolism. As growth rate decreased the proportion of substrate carbon converted into soluble and insoluble melanin increased markedly as is shown by the melanin yield values in Table $\mathrm{I}$. The specific production rates (q-values) of both soluble and insoluble melanin rose considerably when growth rate was reduced from 0.05 to $0.025 \mathrm{~h}^{-1}$.

With respect to both melanin production and R.Q., increasing temperature at constant dilution rate in the chemostat had a similar effect to reducing dilution rate at constant temperature (Table 2). This may be because in both cases a decrease in the ratio of $\mu$ to $\mu_{\max }$ (the maximum growth rate under the prevailing culture conditions) would occur. Trinci (I969) has shown that the growth rate of Aspergillus nidulans in batch culture increases over the range 20 to $37^{\circ} \mathrm{C}$. The $\mathrm{q}-\mathrm{O}_{2}$ rose with increasing temperature although the rate of glucose supply to the culture was kept constant. The reason for this may be an increase in the maintenance energy coefficient (Pirt, 1965) with increasing temperature. Marr, Nilson \& Clark (I963) found that the maintenance coefficient of Escherichia coli was much lower at $15{ }^{\circ} \mathrm{C}$ than at $30^{\circ} \mathrm{C}$. Marr et al. (1963) also suggested that a large portion of the maintenance energy requirement is needed for the resynthesis of protein and nucleic acids during turnover. These turnover rates might be expected to rise when the culture temperature is raised to a supraoptimal value because of increased rates of breakdown of cell macromolecules. The increases in q-melanin values with temperature could be accounted for by the temperature coefficient of an enzyme reaction. In contrast, in colony growth on the medium solidified with agar there was no noticeable effect of temperature on melanin production over the range 22 to $37^{\circ} \mathrm{C}$. At $45^{\circ} \mathrm{C}$ growth on the solid medium was much reduced and melanin production was eliminated. 
Table 2. Relationships between temperature and specific production rates ( $q$-values) of soluble and insoluble melanin, specific oxygen utilization rate $\left(q-\mathrm{O}_{2}\right)$ and respiratory quotient $(R . Q$.

Results are from steady states of a glucose-limited chemostat culture (dilution rate, $0.043 \mathrm{~h}^{-1}$ ).

\begin{tabular}{|c|c|c|}
\hline Temperature & $\begin{array}{l}\text { q-Soluble melanin } \\
(\mathrm{mg} / \mathrm{g} \text { biomass } / \mathrm{h})\end{array}$ & $\begin{array}{l}\text { q-Insoluble melanin } \\
(\mathrm{mg} / \mathrm{g} \text { biomass } / \mathrm{h})\end{array}$ \\
\hline $\begin{array}{l}23{ }^{\circ} \mathrm{C} \\
30^{\circ} \mathrm{C} \\
37^{\circ} \mathrm{C}\end{array}$ & $\begin{array}{l}I \cdot 54 \\
2 \cdot 15 \\
17 \cdot 8\end{array}$ & $\begin{array}{l}1 \cdot 73 \\
2 \cdot 17 \\
2 \cdot 98\end{array}$ \\
\hline & $\begin{array}{c}\mathrm{q}-\mathrm{O}_{2}(\mathrm{mmol} / \mathrm{g} \\
\text { biomass } / \mathrm{h})\end{array}$ & R.Q. \\
\hline $\begin{array}{l}23{ }^{\circ} \mathrm{C} \\
30^{\circ} \mathrm{C} \\
37^{\circ} \mathrm{C}\end{array}$ & $\begin{array}{l}I \cdot 54 \\
2 \cdot 27 \\
3 \cdot 24\end{array}$ & $\begin{array}{l}I \cdot 25 \\
I \cdot I I \\
0 \cdot 9 I\end{array}$ \\
\hline
\end{tabular}

Table 3. Relationships between dissolved oxygen tension and specific production rates ( $q$ values) of soluble and insoluble melanin, specific oxygen utilization rate $\left(q-\mathrm{O}_{2}\right)$ and respiratory quotient (R.Q.)

Results are from steady states of a glucose-limited chemostat culture (dilution rate, $0.04 \mathrm{~h}^{-1}$ ). Results are given in chronological order.

\begin{tabular}{|c|c|c|}
\hline $\begin{array}{l}\text { Dissolved oxygen } \\
\text { tension }(\mathrm{mmHg})\end{array}$ & $\begin{array}{l}\text { q-Soluble melanin } \\
\text { (mg/g biomass } / \mathrm{h} \text { ) }\end{array}$ & $\begin{array}{l}\text { q-Insoluble melanin } \\
(\mathrm{mg} / \mathrm{g} \text { biomass } / \mathrm{h})\end{array}$ \\
\hline 135 & $3 \cdot 64$ & $\mathrm{I} \cdot 8 \mathrm{I}$ \\
\hline 30 & 9.87 & 4.68 \\
\hline 16 & 8.89 & $4 \cdot 2 \mathrm{I}$ \\
\hline $2 \cdot 3$ & 1.03 & $4 \cdot 32$ \\
\hline $\mathrm{I} \cdot \mathrm{I}$ & 0.828 & 3.46 \\
\hline 0.45 & 0.272 & 0.747 \\
\hline 16 & $6 \cdot 20$ & 3.25 \\
\hline \multirow[t]{2}{*}{135} & $4 \cdot 65$ & 1.00 \\
\hline & $\begin{array}{c}\mathrm{q}-\mathrm{O}_{2}(\mathrm{mmol} / \mathrm{g} \\
\text { biomass } / \mathrm{h})\end{array}$ & R.Q. \\
\hline 135 & $\mathrm{I} \cdot 46$ & $I \cdot 13$ \\
\hline 30 & $\mathrm{I} \cdot 32$ & I. 23 \\
\hline $2 \cdot 3$ & I. 17 & I. 38 \\
\hline$I \cdot I$ & 0.828 & I. 58 \\
\hline 0.45 & 0.724 & 1.65 \\
\hline 16 & $\mathrm{I} \cdot 24$ & I. 40 \\
\hline I 35 & $I \cdot 26$ & $I \cdot 15$ \\
\hline
\end{tabular}

Throughout extensive studies of the effects of dissolved oxygen tension on melanogenesis in the chemostat, production of soluble and insoluble melanin appeared to be most favoured within the range 16 to $30 \mathrm{mmHg}$. Lowering the oxygen tension below $16 \mathrm{mmHg}$ progressively reduced melanin production. In one experiment (Table 3) a succession of steady states was obtained at progressively lower values of dissolved oxygen tension down to $0.45 \mathrm{mmHg}$, at which tension melanin production was virtually eliminated. The tension was then raised to give steady states at 16 and $135 \mathrm{mmHg}$ when melanin production by the culture recommenced. Table 3 also shows that at a dissolved oxygen tension between 16 and $2.3 \mathrm{mmHg}$ the respiration rate became limited by the oxygen tension. This result agrees with that of Carter \& Bull (I97I).

Nitrate utilization (mol/1 culture throughput) increased by $40 \%$ when the dissolved oxygen tension was lowered from 30 to $0.45 \mathrm{mmHg}$. At the same time the R.Q. rose markedly. 
Table 4. Relationships between $p H$ value and specific production rates ( $q$-values) of soluble and insoluble melanin, specific oxygen utilization rate $\left(q-\mathrm{O}_{2}\right)$ and respiratory quotient $(R . Q$.

Results are from steady states of a glucose-limited chemostat culture (dilution rate, $0.05 \mathrm{~h}^{-1}$ ).

$\begin{array}{ccc}\text { pH-value } & \begin{array}{r}\text { q-Soluble melanin } \\ (\mathrm{mg} / \mathrm{g} \text { biomass } / \mathrm{h})\end{array} & \begin{array}{c}\text { q-Insoluble melanin } \\ (\mathrm{mg} / \mathrm{g} \text { biomass } / \mathrm{h})\end{array} \\ 7.9 & 23 \cdot 8 & 75 \cdot 3 \\ 6 \cdot 7 & 3 \cdot 22 & 4 \cdot 3 \mathrm{I} \\ 4.0 & \mathrm{I} \cdot 32 & \mathrm{I} \cdot 87 \\ 3 \cdot 0 & 0.5 \mathrm{I} & \mathrm{I} \cdot 8 \mathrm{O} \\ & & \\ & \mathrm{q}-\mathrm{O}_{2}(\mathrm{mmol} / \mathrm{g} & \mathrm{R} \cdot \mathrm{Q} . \\ 7.9 & \mathrm{biomass} / \mathrm{h}) & \mathrm{I} \cdot 04 \\ 6.7 & - & \mathrm{I} \cdot 22 \\ 4.0 & 2 \cdot 03 & \mathrm{I} \cdot 3 \mathrm{I} \\ 3.0 & 2 \cdot 34 & \mathrm{I} \cdot 42\end{array}$

Whether these results were due to the progressive involvement of dissimilatory nitrate reductase as a supplementary respiratory mechanism should, perhaps, be considered. In the absence of an air supply carbon dioxide production by the culture rapidly ceased.

The effects of $\mathrm{pH}$ value upon melanogenesis and gas exchange are shown in Table 4 . The main effect was that melanin production increased markedly with increasing $\mathrm{pH}$ over the range $4 \cdot 0$ to $7 \cdot 9$. Carter (1968) has shown that the phenoloxidase of the strain used has a broad activity peak in the $\mathrm{pH}$ range 6.0 to 8.5 and the activity was not significantly increased when the $\mathrm{pH}$ was raised from $6 \cdot 7$ to $7 \cdot 9$. However, the rate of non-enzymatic oxidative polymerization of DOPA (DL- $\beta$-(3,4-dihydroxyphenyl)alanine) was strongly increased when the $\mathrm{pH}$ was raised over this range. Thus an increase in the rate of non-enzymatic conversion of phenolic precursors to melanin may be the most important factor in the increased melanin production in the chemostat at $\mathrm{pH} 7 \cdot 9$. On reducing the culture $\mathrm{pH}$ value from $3 \cdot 0$ to 2.7 washout began to occur. However, the specific production rates of both forms of melanin rose, that of soluble melanin to approximately $1.4 \mathrm{mg} / \mathrm{g}$ biomass $/ \mathrm{h}$ and that of insoluble melanin to approximately $3.9 \mathrm{mg} / \mathrm{g}$ biomass $/ \mathrm{h}$. These increases may have been caused by the release of metal ions from complex formation with the chelating agent used (citrate).

The increased rates of soluble and insoluble melanin production at a relatively high temperature $\left(37^{\circ} \mathrm{C}\right)$ and $\mathrm{pH}$ value $(7.9)$ in the chemostat were found to be unstable for in both cases the specific rates of melanin production decreased after approximately io to I 5 culture doubling times from the commencement of control at each value.

\section{Melanin production in the chemostat with nitrogen-limited growth}

When growth of Aspergillus nidulans in the chemostat was limited by the nitrogen source (sodium nitrate), melanin production was induced less strongly than when growth was subsequently switched to glucose-limitation. However, when the growth rate was reduced, q-values for both soluble and insoluble melanin rose in a similar manner during nitrogenlimitation to that observed during carbon-limitation of growth (Table 5). Apparently, therefore, irrespective of which nutrient is growth-limiting, reducing the dilution rate tends to cause an increase in the proportion of substrate carbon converted to melanin.

During nitrogen-limitation of growth the $\mathrm{q}-\mathrm{O}_{2}$ value was much lower and the R.Q. much higher than that found at a similar dilution rate when growth was carbon-limited (Table 5). 
Table 5. Effects of growth-limitation by carbon and by nitrogen on melanin production, specific oxygen utilization rate $\left(q-\mathrm{O}_{2}\right)$ and respiratory quotient (R.Q.) of Aspergillus nidulans in chemostat culture

\begin{tabular}{|c|c|c|c|c|c|}
\hline $\begin{array}{c}\text { Growth-limiting } \\
\text { nutrient }\end{array}$ & $\begin{array}{l}\text { Specific } \\
\text { growth } \\
\text { rate } \\
\left(\mathrm{h}^{-1}\right)\end{array}$ & $\begin{array}{l}\text { q-Soluble } \\
\text { melanin } \\
(\mathrm{mg} / \mathrm{g} \\
\text { biomass } / \mathrm{h})\end{array}$ & $\begin{array}{l}\text { q-Insoluble } \\
\text { melanin } \\
(\mathrm{mg} / \mathrm{g} \\
\text { biomass } / \mathrm{h})\end{array}$ & $\begin{array}{l}\mathrm{q}-\mathrm{O}_{2}(\mathrm{mmol} / \mathrm{g} \\
\mathrm{g} \text { biomass } / \mathrm{h})\end{array}$ & R.Q. \\
\hline \multirow[t]{2}{*}{ Nitrogen source } & 0.047 & $2 \cdot 92$ & $\mathrm{I} \cdot 85$ & 0.850 & $2 \cdot 80$ \\
\hline & 0.028 & $5 \cdot 49$ & $2 \cdot 87$ & 0.782 & $2 \cdot 25$ \\
\hline Carbon source & 0.045 & I I $\cdot 7$ & 4.42 & $2 \cdot 38$ & $I \cdot 23$ \\
\hline
\end{tabular}

The reason for this difference in $\mathrm{q}^{-\mathrm{O}_{2}}$ is not clear. However, the relatively high R.Q. values found during nitrogen-limitation of growth may have been caused by alcohol production because ethyl alcohol was qualitatively detected by gas chromatography of a distillate of the culture. In this connexion it should be noted that the dissolved oxygen tension was controlled at $30 \mathrm{mmHg}$, considered to be well in the aerobic range. Thus the ethanol production could be evidence for Crabtree effect, inhibition of respiration by excess glucose (Sols, Gancedo \& DelaFuente, I97I).

The $\mathrm{q}-\mathrm{O}_{2}$ value found during carbon-limitation of growth following nitrogen-limitation was much higher than that previously obtained during carbon-limited growth at $30 \mathrm{mmHg}$ dissolved oxygen tension $(2 \cdot 38$ as opposed to $\mathrm{I} \cdot 32 \mathrm{mmol} / \mathrm{g}$ biomass $/ \mathrm{h})$. This effect of culture history remains unexplained.

\section{The nature of Aspergillus nidulans melanin}

The extreme resistance of Aspergillus nidulans melanin to microbial degradation was shown by repeated failure to isolate a soil micro-organism capable of degrading it. In these studies melanin was incorporated in solid and liquid media as sole carbon source or as sole source of carbon and nitrogen.

Electron microscopy of melanic fungal hyphae revealed that the melanin accumulated on the outer surface of the hyphal wall (Fig. I). The material appeared to have a microfibrillar structure. The melanin claimed to be incorporated in the hyphal walls (Bull, 1970a) was not apparent in electron micrographs. The electron-dense coating on the hyphae could be removed by a vigorous washing procedure. This material was dark and in electron micrographs resembled that coating the wall. The encrustation seen on the walls of melanized hyphae was reduced or absent in mycelium harvested during exponential growth in batch culture before pigment formation had started.

Insoluble melanin isolated from pigmented Aspergillus nidulans mycelium by the method described by Bainbridge et al. (I97I) for standard melanin production contained carbohydrate $(28 \%, \mathrm{w} / \mathrm{w}$, by the anthrone determination). Hyaline mycelium when extracted for melanin gave a much lower yield of product than pigmented mycelium $(3.4 \%, \mathrm{w} / \mathrm{w}$, as opposed to $13 \%, \mathrm{w} / \mathrm{w})$ and this product contained $65 \%(\mathrm{w} / \mathrm{w})$ of carbohydrate. Hence it may be concluded that the carbohydrate extracted was also a component of unmelanized mycelium. No carbohydrate could be detected in samples of precipitated soluble melanin of $A$. nidulans. Thus this may be the purest form of melanin obtained during the investigation.

Elemental analyses of various melanin preparations are shown in Table 6. The nitrogen content of the soluble melanin of Aspergillus nidulans was found to vary considerably with 


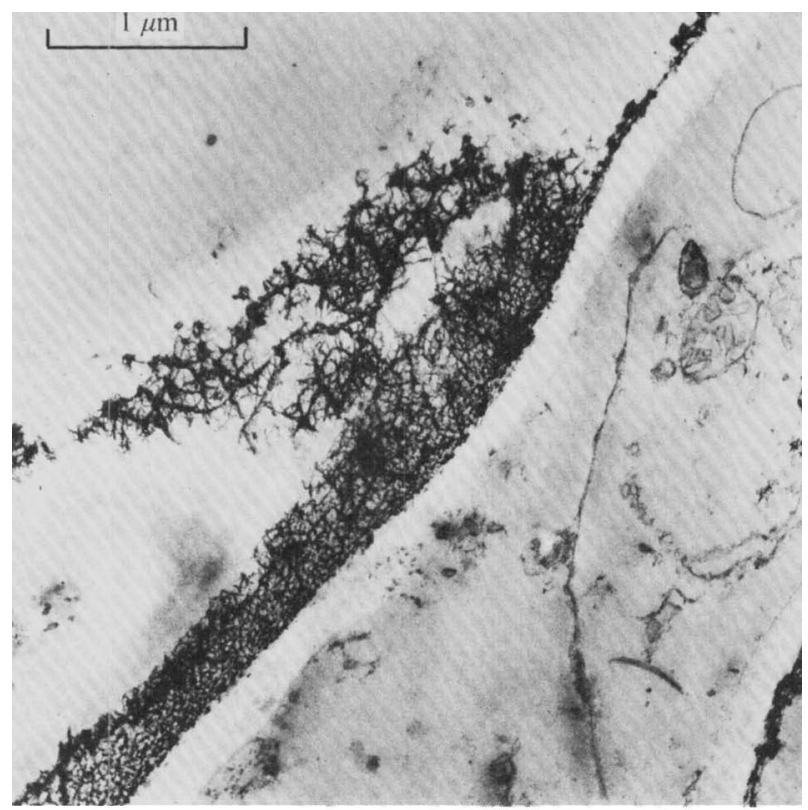

Fig. I (a).

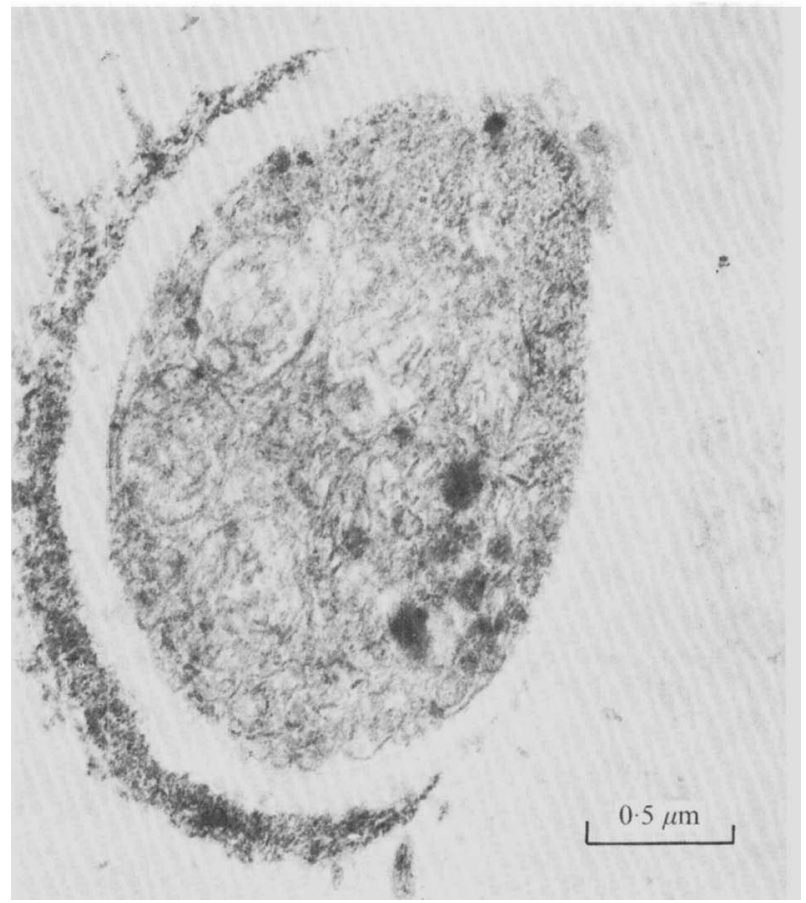

Fig. I (b).

Fig. I. (a) Electron micrograph of sectioned hypha of a highly melanic strain, mel $\mathrm{A}^{\mathrm{x}}$ (Martinelli \& Bainbridge, 1972), of Aspergillus nidulans. Fixation was by glutaraldehyde without osmic acid postfixation. The insoluble melanin is clearly visible as an electron-dense layer outside the hyphal wall. (b) Electron micrograph of transversely sectioned hypha of $A$. nidulans BWB224. Fixation was by glutaraldehyde and osmic acid. The melanin coating may be seen on one side of the hypha. 
Table 6. Elemental analyses of melanins

\begin{tabular}{|c|c|c|c|}
\hline \multirow[b]{2}{*}{ Preparation } & \multicolumn{3}{|c|}{ Percentage values } \\
\hline & C & $\mathrm{H}$ & $\mathrm{N}$ \\
\hline \multicolumn{4}{|c|}{ Aspergillus nidulans melanin } \\
\hline Insoluble (standard) melanin & $44 \cdot 80$ & $5 \cdot 96$ & $4 \cdot 40$ \\
\hline \multicolumn{4}{|c|}{$\begin{array}{l}\text { Samples of precipitated soluble melanin produced in the } \\
\text { chemostat. Unless otherwise stated growth conditions were } \\
\text { as follows: dilution rate, } 0.04 \text { to } 0.05 \mathrm{~h}^{-1} \text {; temperature, } 30^{\circ} \mathrm{C} \\
\text { pH value, } 6.7 \text {; dissolved oxygen tension, } 140 \mathrm{mmHg} \text {. }\end{array}$} \\
\hline Dilution rate, $0.025 \mathrm{~h}^{-1}$ & $59 \cdot 54$ & $6 \cdot 84$ & $3 \cdot 25$ \\
\hline Temperature, $37^{\circ} \mathrm{C}$ & $53 \cdot 50$ & $6 \cdot 00$ & 4.92 \\
\hline $\mathrm{pH}$ value, $7 \cdot 9$ & $52 \cdot 05$ & $6 \cdot 18$ & $5.5 \mathrm{I}$ \\
\hline $\begin{array}{l}\text { Dissolved oxygen tension, } \\
30 \mathrm{mmHg}\end{array}$ & $50 \cdot 48$ & $6 \cdot 65$ & $8 \cdot 88$ \\
\hline \multicolumn{4}{|c|}{ Ustilago melanin (Piattelli, Fattorusso, Magno \& Nicolaus, I963) } \\
\hline & $6 \mathrm{I} \cdot 8 \mathrm{I}$ & $3 \cdot 89$ & Trace \\
\hline \multicolumn{4}{|c|}{ Sepia melanin (Nicolaus, I962) } \\
\hline & $60 \cdot 9$ & $3 \cdot 4$ & $8 \cdot 5$ \\
\hline
\end{tabular}

growth conditions. This suggests that a varying number of indolic subunits were incorporated into the melanin polymer.

DOPA melanin was produced by passing air for several days through a solution of DOPA in $0 \cdot 0$ I $\mathrm{N}-\mathrm{NaOH}$. The polymer produced was precipitated at $\mathrm{pH} 2 \cdot 2 \pm 0 \cdot 2$. Sepia melanin was produced from crude material by extraction with $\mathrm{N}-\mathrm{NaOH}$ as in the production of standard Aspergillus nidulans melanin (Bainbridge et al. 1971). Ultraviolet spectra of $A$. nidulans melanin preparations in $\mathrm{N}-\mathrm{NaOH}$ solution showed a peak at about $290 \mathrm{~nm}$ which shifted to about $280 \mathrm{~nm}$ when the $\mathrm{pH}$ was reduced to $6 \cdot 7$.

The soluble melanin of Aspergillus nidulans exhibited a reversible darkening of the solution when the $\mathrm{pH}$ value was raised from 6.7 to Io. This $\mathrm{pH}$ indicator effect was also shown by slightly oxidized alkaline solutions of DOPA but not by precipitated DOPA melanin or insoluble $A$. nidulans melanin when these materials were dissolved in $\mathrm{N}-\mathrm{NaOH}$ solution, neutralized and added to a range of buffer solutions. When solutions of soluble melanin were heated $\left(90^{\circ} \mathrm{C}, 30 \mathrm{~min}\right)$ a marked darkening without precipitation of melanin occurred and there was a decrease of about $10 \%$ in the concentration of 'total phenols' in the solution determined by the method of Swain \& Hillis (I959). After the heat-treatment the 'indicator effect' previously shown by soluble melanin was eliminated. These results are consistent with the theory that soluble $A$. nidulans melanin on heating is capable of further polymerization and loss of phenolic groups.

\section{DISCUSSION}

The optimum conditions for melanin formation by Aspergillus nidulans are restriction of growth rate to about one-third of the maximum by carbon-limitation, a temperature between 30 and $37{ }^{\circ} \mathrm{C}, \mathrm{pH}$ between 7 and 8 and a dissolved oxygen tension about $20 \%$ of saturation with air at I atm. Although the melanin is characteristically an outer coat on the hyphal surface substantial amounts of soluble melanin may also be formed.

The results show that melanin may now be obtained conveniently in large quantities by fungal culture. Melanin constituted up to $13 \%(\mathrm{w} / \mathrm{w})$ of the mycelial dry weight but soluble melanin precipitated from the culture filtrate may be the best source of pure material. 
Investigations of the nature of melanin are complicated by the fact that both its monomeric subunits and its molecular weight may vary.

The lack of success in isolating a micro-organism able to degrade fungal melanin was in keeping with reports of the extreme resistance of melanized hyphae to microbial lysis (Kuo \& Alexander, 1967; Bull, 1970 b). The position of the melanin on the outside of the hyphal walls indicates a protective function.

It is concluded that melanin production by Aspergillus nidulans is induced or enhanced when the growth rate is restricted. Thus in batch culture melanin formation commences after the termination of the logarithmic growth phase. Although growth-limitation by glucose enhances melanin production, the organism is able to produce melanin in the chemostat when growth is limited by the nitrogen supply and a considerable excess of glucose is present. Thus restriction of the metabolic rate rather than the concentration of any particular substrate appears to be the factor controlling melanin formation.

This work was supported by a grant from the Science Research Council.

\section{REFERENCES}

Andrews, R. S. \& Pridham, J. B. ( 1967). Melanins from DOPA-containing plants. Phytochemistry 6, I3-I8.

Bainbridge, B. W., Bull, A. T., Pirt, S. J., Rowley, B. I. \& Trinci, A. P. J. (1971). Biochemical and structural changes in non-growing maintained and autolysing cultures of Aspergillus nidulans. Transactions of the British Mycological Society 56, 371-385.

BrandT, W. H. (1962). Manganese stimulation of melanin synthesis and microsclerotia development in Verticillium. Plant Physiology, 37, xxx.

Bull, A. T. (1970a). Inhibition of polysaccharides by melanin. Enzyme inhibition in relation to mycolysis. Archives of Biochemistry \& Biophysics 137, 345-356.

Bull, A. T. (1970 b). Chemical composition of wild-type and mutant Aspergillus nidulans cell walls. The nature of polysaccharide and melanin constituents. Journal of General Microbiology 63, 75-94.

CARTER, B. L. A. (I968). Aspects of the physiology of Aspergillus nidulans with reference to phenol oxidase activity. Ph.D. Thesis, Queen Elizabeth College (University of London).

Carter, B. L. A. \& Bull, A. T. (1969). Studies of fungal growth and intermediary carbon metabolism under steady and non-steady state conditions. Biotechnology and Bioengineering II, 785-804.

Carter, B. L. A. \& Bull, A. T. (1971). The effect of oxygen tension in the medium on the morphology and growth kinetics of Aspergillus nidulans. Journal of General Microbiology 65, 265-273.

Carter, B. L. A., Bull, A. T., Pirt, S. J. \& Rowley, B. I. (I971). Relationship between energy substrate utilization and specific growth rate in Aspergillus nidulans. Journal of Bacteriology 108, 309-313.

Durrell, L. W. (I968). Studies of Aureobasidium pullulans (de Bary) Arnaud. Mycopathologia et mycologia applicata 35, II3-120.

HignetT, R. C. \& Kirkham, D. S. (1967). The role of extracellular melanoprotein of Venturia inaequalis in host susceptibility. Journal of General Microbiology 48, 269-275.

Horowitz, N. H. \& SHEN, S.-C. (1952). Neurospora tyrosinase. Journal of Biological Chemistry 197, 513-520.

Kikkawa, H., Ogita, Z. \& Fujito, S. (I955). Nature of pigments derived from tyrosine and tryptophan in animals. Science, New York I2I, 43-47.

Kuo, M.-J. \& AleXANDER, M. (1967). Inhibition of the lysis of fungi by melanins. Journal of Bacteriology 94 , $624-629$.

Maclennan, D. G. \& PirT, S. J. (I967). Automatic control of dissolved oxygen concentration in stirred microbial cultures. Journal of General Microbiology 45, 289-302.

Marr, A. G., Nilson, E. H. \& Clark, D. J. (1963). The maintenance requirement of Escherichia coli. Annals of the New York Academy of Sciences ro2, 536-548.

Martinelli, S. D. \& Brainbridge, B.W. (1972). Phenol oxidases in wild type and mutant strains of Aspergillus nidulans. Journal of General Microbiology. (In the press.)

Mason, H. S. (1959). The structure of melanins. In Pigment Cell Biology. Proceedings of the IVth Conference on the Biology of Normal and Atypical Pigment Cell Growth, pp. 563-582. Edited by M. Gordon. New York: Academic Press. 
Nicolaus, R. A. (1962). Biogenesis of melanins. Rassegna di Medicina Sperimentale 9, (Supplement I), $\mathrm{I}-32$.

Nicolaus, R. A., Piattelli, M. \& Fattorusso, E. (i964). The structure of melanins and melanogenesis. IV. On some natural melanins. Tetrahedron 20, I I63-1 I 72.

Piatelli, M., Fattorusso, E., Magno, S. \& Nicolaus, R. A. (1963). Ustilago melanin, a naturally occurring catechol melanin. Tetrahedron Letters, $\mathbf{1 5}, 997-998$.

PIRT, S. J. (1965). The maintenance energy of bacteria in growing cultures. Proceedings of the Royal Society, London B 163, 224-321.

PIRT, S. J. \& Rowley, B. I. (1969). Melanin production in Aspergillus nidulans. Biochemical Journal 114, 9 P.

REYNOLDS, E. S. (1963). The use of lead citrate at high $\mathrm{pH}$ as an electron-opaque stain in electron microscopy. Journal of Cell Biology 17, 208-212.

Righelato, R. C. \& PIRT, S. J. (1967). Improved control of organism concentration in continuous cultures of filamentous micro-organisms. Journal of Applied Bacteriology 30, 246-250.

Rowley, B. I. (1970). Control of oxygen tension using the Mackereth electrode. In Automation, Mechanization and Data Handling in Microbiology, pp. 163-I74. Edited by A. Baillie \& R. J. Gilbert. London: Academic Press.

Sols, A., Gancedo, C. \& DelaFuente, G. (1971). Energy-yielding metabolism in yeasts. In The Yeasts, vol. 2, p. 30I. Edited by A. H. Rose \& J. S. Harrison. London: Academic Press.

SwaIN, T. \& Hillis, W. E. (1959). The phenolic constituents of Prunus domestica. I. The quantitative analysis of phenolic constituents. Journal of the Science of Food and Agriculture 10, 63-68.

Thomas, M. (1955). Melanins. In Modern Methods of Plant Analysis, vol. 4, pp. 66I-675. Edited by K. Paech \& M. V. Tracey. Berlin: Springer-Verlag.

Trevelyan, W. E. \& Harrison, J. S. (I952). Studies on yeast metabolism. I. Fractionation and microdetermination of cell carbohydrates. Biochemical Journal 50, 298-303.

TrincI, A. P. J. (I969). A kinetic study of the growth of Aspergillus nidulans and other fungi. Journal of General Microbiology 57, $1 \mathrm{I}-24$.

WALTHER, H. J. (1966). On the methods of determining the presence of nitrate in bacteriology. Archiv für Hygiene und Bakteriologie 150, I70-179. Cited in Biological Abstracts 48, 96980 (1967). 